\title{
Claves para la comprensión de la interdependencia entre la cultura organizacional y el desempeño institucional: caso de la institución educativa Fe y Alegría $\mathrm{N}^{\circ} 02$
}

Christian Trujillo*

* Licenciado en Sociología por la Pontificia Universidad Católica del Perú (PUCP). Ha laborado en el Centro de Investigaciones y Servicios Educativos (CISE) de la PUCP, Arellano Marketing y en otras consultoras particulares. Correo electrónico: trujillo.christian@pucp.pe. https://orcid. org/0000-0001-9206-8069

Fecha de recepción: 28/01/20.Fecha de aceptación: 23/06/2020 


\title{
Claves para la comprensión de la interdependencia entre la cultura organizacional y el desempeño institucional: caso de la institución educativa Fe y Alegría $\mathrm{N}^{\circ} 02$
}

\section{RESUMEN}

Si bien se ha producido una amplia bibliografía nacional e internacional para explicar el éxito de la gestión educativa en la Red Fe y Alegría, las diferentes aproximaciones a este fenómeno educacional han omitido un análisis histórico de la influencia del proceso de desarrollo organizacional sobre aspectos performativos, como el desempeño institucional. Considerando tal premisa, se ha seleccionado el caso de la institución definitiva (I.E.) Fe y Alegría $\mathrm{N}^{\circ}$ 02, el cual, con su experiencia, permite responder la siguiente pregunta: ¿de qué manera las trasformaciones que acontecieron en la cultura organizacional entre los años 1980 y 2017 influyeron sobre el actual desempeño institucional? La evidencia muestra que existe un proceso complejo denominado «mitificación de reglas y perfiles». Dicho proceso, aunque aún no se ha explorado a profundidad en la literatura, repercute sobre su sistema de gestión institucional, legitima la toma de acciones y la autoridad dentro del plantel y coexiste en paralelo a un fenómeno de acoplamiento técnico e institucional. Finalmente, se concluye que este plantel educativo es un espacio de resistencia frente a la influencia de premisas organizacionales del mundo empresarial, a pesar de usar racionalmente recursos escasos en un contexto de precariedad.

Palabras clave: cultura organizacional, acoplamiento técnico, espacios de participación escolar, mitificación de reglas y perfiles, gestión educativa.

Keys to understanding the interdependence between organizational culture and institutional performance: The case of the educational institution Fe y Alegría $\mathrm{N}^{\circ} 02$

\begin{abstract}
Although an extensive national and international bibliography has been produced to explain the success of educational management in the I.E. Fe y Alegría, the different approaches about it have omitted a historical analysis of the influence of the organizational development process on performative aspects, such as institutional performance. Considering this premise, the case of the I.E. Fe y Alegría $\mathrm{N}^{\circ} 02$, with its experience, allows us to answer the following question: in what way did the transformations, that occurred in the organizational culture between the years 1980 and 2017, influence current institutional performance? The evidence shows that there is a complex process called «mythification of rules and profiles». This process, even though it has not yet been explored in depth in the literature, has repercussions on its institutional management system, legitimizes the taking of actions and authority inside the educational campus, and coexists in parallel with a phenomenon of technical and institutional coupling. Finally, it is concluded that this educational establishment is a space of resistance against the influence of organizational premises of the business world; despite rationally using limited resources in a precarious context.
\end{abstract}

Keywords: organizational culture, technical coupling, spaces for school participation, mythification of rules and profiles, educational management. 


\section{INTRODUCCIÓN}

En el mundo escolar, el desempeño institucional alude al mejor manejo de los recursos materiales y humanos (ambos recursos técnicos), además de la optimización de procesos administrativos. En particular, la presente investigación entiende al desempeño institucional como una caracterización de las prácticas asociadas a dos dimensiones del trabajo escolar: (i) la gestión educativa, y (ii) los espacios participativos (Hernández, 2009). En otras palabras, desde una perspectiva cualitativa, observar y analizar el desempeño institucional solo es posible si antes se identifica algún tipo de impacto de la cultura organizacional sobre las dos dimensiones señaladas. La figura 1 representa con mayor claridad lo expuesto:

Figura 1. Impacto de la cultura organizacional sobre el desempeño institucional

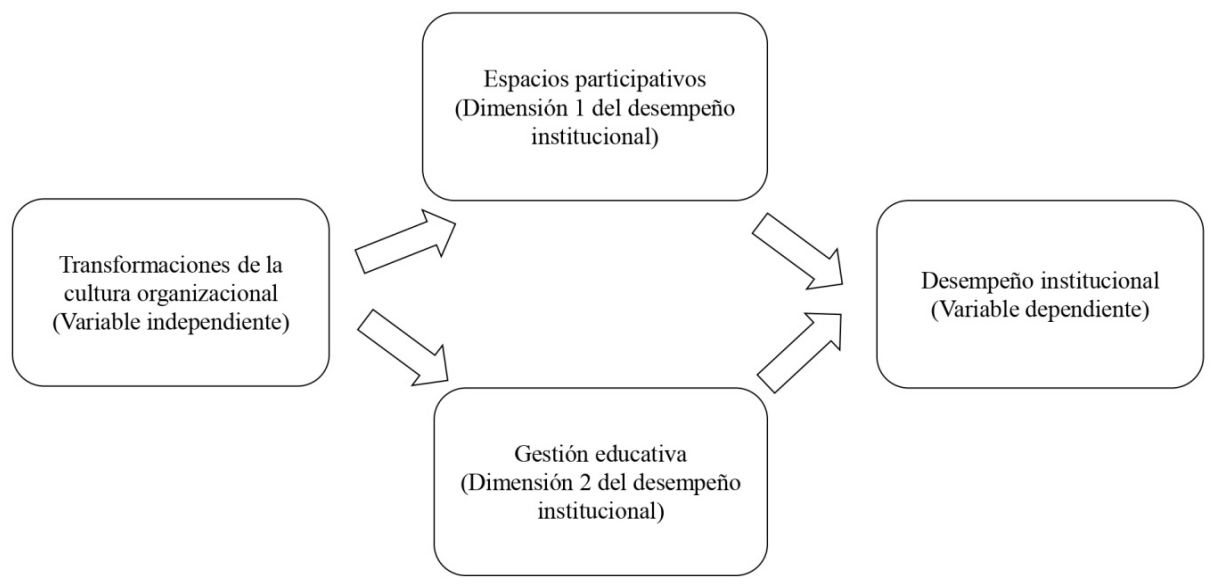

Una de las instituciones que pueden ayudar a reflexionar sobre la interrelación entre las transformaciones de la cultura organizacional y el desempeño institucional es la experiencia educativa de uno de los primeros colegios de la red Fe y Alegría ${ }^{1}$, instalada en el Perú durante la década de 1960: la I.E. Fe y Alegría Nº2, ubicada en el distrito limeño de San Martín de Porres y concebida como un proyecto comunitario (la comunidad circundante, la Congregación Hermanas del Amor de Dios y la Oficina Central Fe y Alegría en el Perú). Desde sus inicios, la I.E. apostó por una educación inclusiva para los más pobres, se posicionó en un lugar de carencia extrema e insistió en apoyar una educación para el trabajo. Tras largos ańos de

\footnotetext{
1 Conformada por 81 planteles que están en veinte regiones del Perú. Brinda educación a más de 84000 niños, niñas y jóvenes.
} 
funcionamiento, fue pionera en el empleo de nuevos modelos de planificación curricular ${ }^{2} \mathrm{y}$, paulatinamente, orientó su gestión institucional a ser democrática, participativa, abierta al cambio, y que enfrenta los retos educativos actuales.

El éxito de la I.E. Fe y Alegría $\mathrm{N}^{\circ} 02$ no resulta gratuito. Para ello, en algunas situaciones, se ha implementado un proceso de emparejamiento (Parra $\&$ Wodon, 2011), proceso por el cual se apoya a la población estudiantil con menor rendimiento académico con el fin de nivelarlos. En otros casos, el éxito de la institución educativa está asociado a la tarea continua de supervisión, monitoreo y evaluación de docentes, acompañada y respaldada por padres de familia con una participación guiada y activa (Alcázar \& Cieza, 2002). Como queda en evidencia, el concepto de escuela en la I.E. Fe y Alegría $N^{\circ} 02$ implica un rol activo de los padres y las madres de familia en la labor educativa de sus hijos (Incio, 2015; Alcázar \& Valdivia, 2011). Es a través de este tipo de disposiciones como Fe y Alegría crea un sentimiento de pertenencia o un clima de familiaridad entre sus miembros, según señalan Parra y Wodon (2011).

Ciertamente, toda I.E. con un gran número de oficinas necesita un órgano que centralice la gestión. En el caso de la red Fe y Alegría, tal órgano ha sido la Oficina Central Fe y Alegría. De ahí que, para algunos estudiosos, este sea el elemento de gestión esencial (Stojnic \& Consiglieri, 2015; Alcázar \& Valdivia, 2011). Como bien es sabido, un centralismo extremo en todo sistema de gestión genera múltiples problemas. En ese sentido, la I.E. Fe y Alegría $N^{\circ} 02$ lidia con este reto a través de la aplicación y la práctica de estrategias participativas que toman en cuenta prácticas sociales y culturales para obtener avances en los procesos de aprendizaje (Gutiérrez, 2013).

$\mathrm{Al}$ analizar los estudios previos, se llegó a la conclusión de que no hacen más que corroborar los buenos resultados en torno al desempeño institucional y el buen rendimiento de su comunidad estudiantil. A manera de síntesis, tal éxito está relacionado con tres aristas: (i) los procesos organizacionales complejos internos; (ii) los tipos de recursos educativos utilizados, y (iii) la gestión racional optimizadora de recursos. Sin embargo, se pasa por alto —en muchos de estos estudios - ahondar sobre la capacidad y la flexibilidad de las I.E. Fe y Alegría (en este caso, la I.E. Fe y Alegría $N^{\circ}$ 02) para implementar y probar programas innovadores con una intervención educacional contextualizada. Más aún, mucha de esa literatura no hace visible que el buen desempeño institucional de la red Fe y Alegría responde a un proceso largo de desarrollo y consolidación. En ese sentido, resulta pertinente incluir una perspectiva histórica a las futuras investigaciones con el objetivo de dar luces sobre el estado actual de la institución educativa evaluada.

\footnotetext{
2 Doble T de Martiniano.
} 


\section{Marco TEÓrico}

En seguida, se presenta una serie de aproximaciones a la cultura organizacional, la gestión educativa y los espacios participativos. El objetivo de ello es generar un debate entre dichos conceptos para obtener una nueva metodología de estudio, es decir, identificar indicadores que, bajo una perspectiva cualitativa e histórica, profundicen en la complejidad que se oculta detrás de un tradicional análisis cuantitativo del desempeño institucional.

\section{Teoría de la cultura organizacional}

Para la presente investigación, se entiende la cultura organizacional como «un proceso productivo de construcción sociohistórico del sistema de significados que configuran la vida cotidiana de las personas» (Goméz, 1994, p. 139). Asimismo, Arthur Zimmermann (2000) sostiene que dicha cultura organizacional en la empresa aporta elementos muy importantes al funcionamiento organizacional, pues genera vínculos, seguridad, integración e identificación, construye una idea de orden y justicia social, y, además, justifica la razón de actuar e impulsa la construcción de planes de vida a futuro.

De acuerdo con la teoría industrial o empresarial, la cultura organizacional tiene tres niveles. Un primer nivel es la manifestación externa de la cultura de la empresa. En dicho nivel, lo objetivado es explícito y consciente (ejemplo: objetos simbólicos, formas lingüísticas o personajes simbólicos). Un segundo nivel es lo no observable $^{3}$. Y un tercer nivel es cuando la cultura se reifica y se posiciona en el sentido común del grupo. Cabe señalar que para la presente investigación se han tomado en cuenta los dos últimos niveles. Sin embargo, más allá de los niveles identificados, es importante recalcar que el cambio — según el caso estudiado— se da a partir de la presencia de motores que lo incentivan: innovación, contexto y conflicto.

En efecto, la cultura organizacional cambia constantemente. Esta mutabilidad da lugar a la aparición de un elemento esencial: el acoplamiento. Bajo la teoría del nuevo institucionalismo, se hace alusión a la influencia que ejerce la institucionalización de los sistemas educativos sobre la manera en que la propia organización asume el reto interno de afrontar el cambio. Para lograrlo, se requiere mejorar procesos, optimizar el uso de recursos (materiales, sociales o culturales) y conseguir que los educandos tengan el mejor rendimiento escolar posible. Dos son sus elementos: (i) el núcleo técnico de la organización, y (ii) la autoridad.

En cuanto al primer elemento, Weick (1976) refiere que, «en el caso del acoplamiento técnico, cada elemento representa algún tipo de tecnología, tarea, subtarea,

\footnotetext{
3 Se asocia a los contenidos o significados detrás de las manifestaciones internas de la cultura.
} 
rol, territorio y persona, y los acoplamientos son inducidos por la tarea» (p. 4). Cabe resaltar que dicho concepto guiará la presente investigación. Al respecto, según se puede corroborar, gran parte de la literatura explica el fenómeno técnico a partir de la existencia de procesos de socialización común. No obstante, también se explica por la presencia de obligaciones implícitas en la asignación de recursos de un nivel jerárquico del sistema escolar (Gamoran \& Dreeben, 1986, pp. 614-615). En relación con la autoridad, Weick (1976) señala un grupo de elementos que ejercen control para el cumplimiento de tareas dadas al personal de una organización. Este cumplimiento implica un proceso de certificación y una importante práctica de la inspección. En suma, estos dos elementos evocan cuán débil o fuertemente están acoplados los sistemas a la organización, o viceversa.

\section{Teoría de la gestión educativa}

Según se ha mencionado, analizar la autoridad como un elemento que acompaña al acoplamiento técnico exige revalorar la gestión educativa, pues ambos crean una interdependencia: no hay gestión sin acoplamiento, al igual que no hay acoplamiento sin gestión. Para la literatura revisada, la gestión educativa, como una forma de certificación o inspección, genera varios niveles de acoplamiento. En un primer nivel de acoplamiento, se halla el grado de vinculación entre el Estado y la organización educativa. Resulta pertinente entender que las organizaciones educativas tienen el imperativo de acoplarse a los requerimientos establecidos por el Estado. Al respecto, Santizo (2011) identifica:

La política de participación social enfrenta un dilema, ya que hay dos valores en conflicto: por un lado, la libertad de acción que se desea otorgar a las escuelas, y por otro, la necesidad del Estado de mantener una coordinación para orientar la política educativa (p. 759).

En un segundo nivel de acoplamiento, se encuentra el grado de acción que tienen los actores para cumplir sus funciones sin obstruirse entre ellos. Para lograrlo, es necesario implementar formas de coordinación y comunicación que sean acompañadas por el establecimiento de funciones y roles delimitados para cada actor. En el caso peruano, la existencia de la Ley General de Educación contribuye a hacer frente a tal desafío. Su ausencia puede originar problemas de intromisión, por ejemplo, en la labor entre maestros y padres. En ese sentido, mientras la labor docente sea más especializada, es posible que ocasionalmente se genere un rechazo en adherir observaciones provenientes de poblaciones consideradas «no especializadas» (padres, madres, alumnos y otros).

En un tercer nivel de acoplamiento, se ubica el grado en el cual la acción real de los agentes educativos se cruza con los esquemas formales de su función. Resulta 
ingenuo pensar que la «forma de vivir, pensar o sentir» (según Bourdieu, habitus) en la participación de las familias es igual al que fomenta o quiere implementar el centro educativo. Por un lado, se buscan estrategias para que los miembros de la comunidad educativa cumplan con la tarea asignada. Por otro, es importante poner énfasis sobre la labor de los directores de las instituciones educativas, pues ellos son un filtro entre el modelo ideal y el modelo práctico. La gestión educativa debe intervenir en espacios relacionados con lo interpersonal, subjetivo o cognitivo. En torno a este debate, se señala que "para promover la colaboración se debe formalizar la confianza a fin de volver estables las relaciones y es necesario crear un liderazgo compartido y no centralizado» (Santizo, 2011, p. 756).

En un cuarto nivel de acoplamiento, se encuentra el grado de sujeción que los propios actores educativos desarrollan y se exigen acatar. Al respecto, ciertos estudios muestran un desplazamiento en la participación de un sentido democrático y colectivo a uno individual y de mercado (Yuli et al., 2004). Otros estudios afirman que la reproducción de una lógica paternal-familiar concibe a los niños y adolescentes como sujetos con derechos de protección, asistencia y cuidado. Bajo tal consigna, los adultos e infantes se disponen como dos categorías diferentes y en relación vertical. Con ello, se rompe una de las condiciones necesarias para una gestión participativa en la escuela: reconocer a los diferentes actores educativos como sujetos merecedores de los mismos derechos y deberes.

\section{Teoría del espacio participativo}

En la red Fe y Alegría, la participación ha sido un eje central de la gestión educativa. Ella ha generado espacios donde se puede germinar, evolucionar y fortalecer elementos propios. Teóricamente, la participación incide sobre aquellos factores que impulsan a los individuos a trabajar en colectivo, tomar decisiones conjuntas o realizar tareas de coordinación y consenso. Ello demanda la existencia de un habitus participativo en cada uno de los miembros de la comunidad educativa, así como de disposiciones estructurales (historia, cultura y tradiciones). Por otro lado, la participación es una herramienta de eficiencia y mejoramiento de la calidad educativa, un instrumento de control ciudadano y un proceso de aprendizaje comunitario (Eguren, 2006). En ella, la codecisión puede mejorar la convivencia entre sus miembros si se emplea de manera adecuada (Sánchez, 2013). No obstante, el presente estudio considera que la participación es un mecanismo de acoplamiento moderno exigido, con una fuerte influencia en los niveles de acoplamiento expuestos anteriormente.

Como es sabido, la participación se da en un campo muy específico: el educativo. Según el sociólogo francés Pierre Bourdieu (1996), en dicho campo, las relaciones entre sus miembros pueden llegar a ser conflictivas, ya que se genera un ambiente competitivo basado en la lucha por lograr el mejor posicionamiento social. En el 
campo educativo, también se reproducen relaciones de dominación, formas de conciencia y representaciones ideológicas que otorgan legitimidad. Es decir, impone y reproduce las estructuras sociales y transforma desigualdades sociales en desigualdades naturales (inculca o apropia un habitus). Cabe resaltar que el ejercicio del poder simbólico juega un papel central en la legitimación de las relaciones sociales. Ello se despliega a través del empleo de toda acción pedagógica. Colateralmente, el trabajo pedagógico influye en la personalidad. Con ello, se consigue que lo social se incorpore a lo individual y, en tanto lo individual se adhiera el cuerpo (actitudes, sentimientos, expresiones u corporales), se convierte en un cuerpo socializado. En este proceso, resulta pertinente seńalar que la familia ejerce una acción pedagógica tanto o más importante que la institución educativa.

$\mathrm{Al}$ igual que en otras esferas de la vida social, el campo educativo no es ajeno al influjo del sistema capitalista ni de los procesos de racionalización en los cuales se erige. Sobre esa base, en la actualidad, los elementos tradicionalmente vinculados con el sector industrial o empresarial son usados por muchas instituciones educativas para medir el desempeño institucional y el rendimiento del alumnado mediante indicadores de eficiencia, efectividad y eficacia.

Asimismo, se suele omitir el hecho de que las escuelas contienen múltiples espacios. Uno de ellos, fuertemente ligado a la gestión educativa actual, es el de los espacios de participación. Para entenderlos, es importante incidir sobre la naturaleza de la participación. Según Lefebvre (1976), filósofo y sociólogo francés, tres son las dimensiones del espacio: (i) la práctica espacial (espacio físico); (ii) las representaciones del espacio (espacio mental), y (iii) los espacios de representación (espacio social). Cabe precisar que Lefebvre (1976) habla en términos de espacio público y sus dimensiones. Sin embargo, se debe agregar una dimensión adicional al espacio concebido por el autor francés en tanto el estudio se enmarca dentro del campo educativo: el espacio pedagógico (espacio en donde se dan múltiples formas de trasmisión de conocimientos). Como bien señala Lefebvre, el espacio en tanto territorio genera disputas de múltiple causalidad. Una alternativa para poder lidiar con dicha conflictividad es generar y ejecutar mecanismos participativos para promover el consenso. Ello da como resultado la generación de un modelo de gestión participativo.

\section{ОвJETIVOS}

El objetivo principal del estudio es ahondar en la influencia provocada por los cambios de la cultura organizacional de la I.E. Fe y Alegría $\mathrm{N}^{\circ} 02$ sobre su desempeño institucional y, en esa medida, analizar el papel de los espacios participativos como componentes para afrontar el cambio institucional desde la década de 1980 hasta la 
actualidad. Para ello, se contrastan tres de sus períodos de desarrollo, identificados con la ayuda de esfuerzos similares realizados previamente ${ }^{4}$. En busca de la mayor objetividad, un hito específico marcará el inicio de cada uno de los períodos de la institución educativa. Cabe precisar que existe un continuo entre las décadas de 1960 y 1980, motivo por el cual dicho período no pertenece al tiempo de análisis. Ello se puede corroborar a través de las entrevistas hechas.

Con respecto al primer hito, se llegó a identificar que en 1980 la «escuela» Fe y Alegría $N^{\circ} 02$ se convierte en el «colegio» Fe y Alegría $N^{\circ} 02$. El cambio de denominación implicó expandir el servicio educativo y asumir los retos que conllevaba. El segundo hito ocurre en la década de 1990, exactamente en marzo de 1994. En dicho momento, la hermana Julia Martínez asume la dirección del plantel y, de esa manera, se abre paso a una nueva etapa en la vida institucional. Adicionalmente, se pone énfasis sobre el tema pedagógico, así como también se sientan las bases de la labor educativa en los próximos años. Finalmente, el último hito que marca el inicio del tercer período acontece en 2000. Para ese entonces, se comienza la programación denominada Doble $\mathrm{T}$ de Martiniano en secundaria y, paralelamente, se inician los Proyectos Educativos Institucionales (PEI). Con ambos acontecimientos, se ocasiona un giro en la forma de canalizar y organizar el trabajo educativo dentro del plantel:

Tabla 1. Periodización de historia de la I.E. Fe y Alegría $N^{\circ} 02$

\begin{tabular}{llll}
\hline \multicolumn{1}{c}{ Periodización } & \multicolumn{1}{c}{$\begin{array}{c}\text { Período 1 } \\
(\text { 1980-1989) }\end{array}$} & \multicolumn{1}{c}{$\begin{array}{c}\text { Período 2 } \\
(\text { 1990-1999) }\end{array}$} & \multicolumn{1}{c}{$\begin{array}{c}\text { Período 3 } \\
(\text { 2000-2017) }\end{array}$} \\
\hline $\begin{array}{l}\text { Periodización para la Red } \\
\text { Fe y Alegría }\end{array}$ & $\begin{array}{l}\text { Etapa de preocupación } \\
\text { por la calidad educativa }\end{array}$ & $\begin{array}{l}\text { Etapa de emprendimiento } \\
\text { de proyectos educativos }\end{array}$ & $\begin{array}{l}\text { Etapa de fortalecimiento } \\
\text { institucional }\end{array}$ \\
\hline $\begin{array}{l}\text { Periodización para la I.E. } \\
\text { Fe y Alegría } N^{\circ} \text { 02 }\end{array}$ & $\begin{array}{l}\text { Hito: en 1980, la «escuela } \\
\text { Fe y Alegría» se convierte } \\
\text { en el «colegio Fe y } \\
\text { Alegría» }\end{array}$ & $\begin{array}{l}\text { Hito: en marzo de 1994, } \\
\text { asume la dirección del } \\
\text { I.E. Fe y Alegría } N^{\circ} \text { 02 la la } \\
\text { hermana Julia Martínez }\end{array}$ & $\begin{array}{l}\text { Hito: en secundaria, se } \\
\text { comienza la programación } \\
\text { denominada Doble T de } \\
\text { Martiniano }\end{array}$ \\
\hline
\end{tabular}

Para conseguir el objetivo principal, la investigación abordará los siguientes objetivos específicos: (i) identificar los cambios en la gestión educativa de la I.E. Fe y Alegría $\mathrm{N}^{\circ} 02$, y (ii) analizar posibles efectos sobre el desempeńo institucional al implementar y ejecutar procesos participativos dentro del plantel.

\footnotetext{
4 Cronológica del padre Cuquerella del proceso del desarrollo de la I.E. Fe y Alegría No 02 y compi-
} lación de los momentos históricos consignados en los Proyectos Educativos Institucionales (PEI). 


\section{HiPóTESIS}

Como postulado principal, se propone que el desempeńo institucional de la I.E. Fe y Alegría $\mathrm{N}^{\circ}$ 02, en los últimos 37 años, ha sufrido cambios debido al impacto de las transformaciones en su cultura organizacional sobre dos de sus dimensiones histórico-sociales: (i) los espacios participativos, y (ii) la gestión educativa. Sobre la primera de estas dimensiones, se entiende que la gestión educativa ha experimentado un proceso de racionalización institucional. Esto ha implicado la apropiación y la concreción de valores y objetivos del mundo empresarial. Con respecto a la segunda dimensión, se propone que las transformaciones organizacionales están altamente relacionadas con la incorporación de procesos participativos. Ello ha ocasionado una mayor apertura de espacios de concertación y diálogo en la institución educativa, basados ya no solo en principios de ética cristiana, sino también del mundo empresarial.

\section{MÉTOdo Y ANÁLISIS DE DATOS}

Para fines metodológicos, se optó por elaborar un estudio de caso de tipo diacrónico y cualitativo. Para desarrollar dicha perspectiva, el acopio de la información se logró a través de entrevistas semiestructuradas y un análisis documental. En cuanto a las entrevistas, por medio de la técnica bola de nieve, se procedió a seleccionar colaboradores (autoridades, docentes, estudiantes y madres) según su nivel de participación y su condición dentro de la institución educativa, en un principio, con ayuda de la directora y subdirectora del plantel. Asimismo, se agrupó a estos actores en tres categorías, estrechamente vinculados con los tres períodos identificados en el cuadro 1. Fueron en total 34 las personas entrevistadas entre octubre de 2017 y febrero de 2018.

Por medio de entrevistas grupales e individuales de aproximadamente una hora de duración, y con el fin de medir el desempeño institucional de la I.E. Fe y Alegría $\mathrm{N}^{\circ}$ 02, se indagó sobre los tres aspectos del marco teórico ya previamente presentados. Resulta importante señalar que las percepciones en torno a estos tres aspectos se hicieron considerando el rol que tenía el entrevistado en un momento determinado. Así, se llevaron a cabo entrevistas al equipo directivo, los representantes de los grupos organizados y los miembros, organizados o no, de la I.E. Fe y Alegría No 02, que hubieran formado o formen parte de la institución educativa en los períodos estudiados. Posteriormente, una vez hecho el acopio de información, se procedió a aplicar la técnica de análisis discursivo, que aborda el lenguaje como un evento comunicativo dentro de un contexto en donde se sitúan las interacciones humanas (Urra et al., 2013). 
Adicionalmente, en lo que se refiere al análisis documental, el presente estudio se centró en los PEI del plantel. Tales documentos son una herramienta de gestión institucional que actualmente el Ministerio de Educación del Perú (Minedu) exige elaborar a las autoridades de cada institución educativa del país, en compañía de las comunidades educativas que las lideran. Cabe precisar que, aunque no se pudo acopiar los PEI o documentos similares en la década de 1980 — pues no se elaboraban-, sí se logró conseguir los PEI de la década de 1990 y, posteriormente, los PEI desarrollados desde 2000 hasta la actualidad. En ellos, se contrastaron aspectos transversales para identificar el cambio o constancia de la cultura organizacional en la institución educativa.

Finalmente, una vez realizadas todas las entrevistas, se organizó la información con la ayuda de una matriz. Por su parte, algo similar se utilizó para sistematizar la información acopiada de los PEI. Con ambos insumos, se realizó el análisis y la triangulación de la información.

\section{Resultados}

\section{Resultados de la cultura organizacional}

La experiencia de la I.E. Fe y Alegría $\mathrm{N}^{\circ} 02$ concuerda con la propuesta de cultura organizacional señalada por Gómez (1994). Es decir, se manifiesta un posicionamiento inicial de valores ${ }^{5}$ (por ejemplo, la solidaridad) adheridos fuertemente sobre todos los miembros de la institución educativa a lo largo del tiempo. Este posicionamiento no ha sido un proceso inmediato; por el contrario, ha demandado un largo período de maduración. Muchos de los valores mencionados en un contexto de precariedad, como el de San Martín de Porres en la década de 1960, empataron con las necesidades éticas y morales que la población local necesitaba en ese momento histórico. En seguida, se afirma que existen valores adaptados a las demandas del tiempo presente:

En general, pienso que se han mantenido los grandes valores sociales, que son, como decía mi colega, la solidaridad, la responsabilidad, la honestidad [...] sino que ahora se han adecuado a estos tiempos (madre de familia durante la década de 1980. Comunicación personal, 15 de febrero de 2018).

También se indica que hay valores del pasado reafirmados a pesar del tiempo transcurrido:

Son los mismos valores los que se practican en la institución desde los 90. Unos con más fuerza y otros con más debilidad [...] siempre vuelven (estudiante

\footnotetext{
Según el proyecto de Pastoral Juvenil Vocacional, creado en la I.E. Fe y Alegría Nº2, estos valores son de carácter cristiano.
} 
durante la década de 1980 y auxiliar de educación destacada en la biblioteca del plantel en 2017. Comunicación personal, 20 de noviembre de 2017).

Asimismo, se señala que los altos cargos deben mostrar solidaridad y respeto al alumnado:

Creo que la solidaridad y el respeto, eso es muy fundamental para mí, porque siento que, con este cargo, ahora más que nada, puedo apoyar mucho a los estudiantes que necesitan de mi ayuda [...] puedo respetar las opiniones a la hora del municipio escolar (alcaldesa del municipio escolar en 2017. Comunicación personal, 30 de octubre de 2017).

Además, se apunta la contante preocupación por mantener el orden y la limpieza:

Hoy en día, ahora que ya tengo a mis niños aquí, hay algo muy importante [...] el orden, la limpieza, que sí arreglamos acá, en comparación de otros sitios que no encuentras nada [...] y acá sí están pendientes (estudiante durante la década de 1990 y madre de familia en 2018. Comunicación personal, 13 de febrero de 2018).

De forma sintética, se organizan todos los valores mencionados por los entrevistados de la siguiente manera:

Tabla 2. Valores de la I.E. Fe y Alegría $\mathrm{N}^{\circ} 02$ por período de análisis según entrevistados

\begin{tabular}{|c|c|c|c|}
\hline & $\begin{array}{c}\text { Etapa de preocupación } \\
\text { por la calidad educativa } \\
(1980-1989)\end{array}$ & $\begin{array}{c}\text { Etapa de emprendimiento } \\
\text { de proyectos educativos } \\
(1990-1999)\end{array}$ & $\begin{array}{c}\text { Etapa de fortalecimiento } \\
\text { institucional } \\
(2000-2017)\end{array}$ \\
\hline & 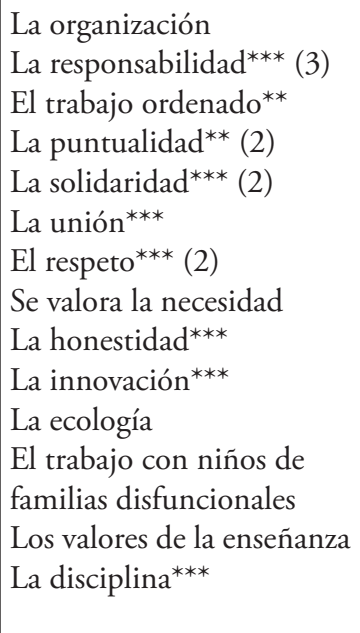 & $\begin{array}{l}\text { La innovación*** } \\
\text { Búsqueda de lo mejor para } \\
\text { los alumnos } \\
\text { La solidaridad*** } \\
\text { La responsabilidad*** }(2) \\
\text { La honestidad*** } \\
\text { La puntualidad** } \\
\text { La preocupación del padre } \\
\text { por su hijo } \\
\text { La unión*** (entre padres } \\
\text { o abastecer al colegio) } \\
\text { La limpieza } \\
\text { El orden** } \\
\text { La participación } \\
\text { El respeto*** } \\
\text { La disciplina*** }\end{array}$ & $\begin{array}{l}\text { La responsabilidad }{ }^{* * *}(3) \\
\text { El respeto } \\
\text { El carińo (el amor entre todos, } \\
\text { el amor al prójimo) (5) } \\
\text { La calidad } \\
\text { La solidaridad*** (8) } \\
\text { La honestidad*** (3) } \\
\text { La autorregulación } \\
\text { La autoformación } \\
\text { La disciplina*** (3) } \\
\text { La unión*** (3) } \\
\text { La confianza } \\
\text { La innovación*** } \\
\text { El apoyo al grupo (3) } \\
\text { Tener competencias y } \\
\text { capacidades }\end{array}$ \\
\hline
\end{tabular}

Fuente: Elaboración propia. ${ }^{* * *}=$ se repite en los tres períodos, ${ }^{* *}=$ se repite en dos períodos, si no aparece un ${ }^{*}=$ solo se hace mención en un período de análisis y () = número de veces que se hace mención por un actor diferente. 
Resulta importante mencionar que la transmisión de estos valores no resulta fortuita. Ello se debe, en gran medida, a la práctica y el ejemplo dejado por las autoridades (es decir, las hermanas) y los docentes del plantel durante más de treinta años de vida institucional.

A continuación, se menciona que la abnegación constante en la labor docente es reconocida y admirada hasta hoy en día:

Lo que sí recuerdo mucho, y que me marcó bastante, era que mi profesora era muy dedicada, se daba tiempo para los 54 estudiantes que había en el aula. [...] se daba tiempo para revisar los cuadernos, buena presentación personal, los problemas internos que había en el aula, no sé cómo [...] y siempre, hasta ahora, porque tenemos nuestras reuniones de promoción (estudiante durante la década de 1980 y docente de computación en secundaria en 2017. Comunicación personal, 3 de noviembre de 2017).

$\mathrm{Al}$ pasar las décadas, la I.E. Fe y Alegría $\mathrm{N}^{\circ} 02$ enfocó su trabajo sobre aquellos principios organizacionales que permiten el adecuado funcionamiento de una institución educativa. Según Gento (1996), estos principios son la unicidad, la autoridad, la motivación y la competencia funcional (ver anexo, cuadro 3).

En términos generales, se halló que los valores específicos de la institución educativa identificados por los entrevistados son la solidaridad, la responsabilidad, la honestidad, la disciplina, la innovación, la unión y el respeto. Con este grupo de valores, la institución ha transferido a los actores locales y educandos una concepción de escuela que garantice su funcionamiento a lo largo de los años. Siguiendo a Zimmermann (2000), la I.E. Fe y Alegría $N^{\circ} 02$ ha forjado con perseverancia y constancia una cultura organizacional donde se percibe una atmósfera de seguridad, integración, identificación, orden y justicia social. Además, la escuela ha transferido a sus integrantes la idea de poder construir planes de vida a futuro y reforzar los roles que cumplen algunos de sus miembros. Cabe destacar que la cultura organizacional de la I.E. Fe y Alegría $\mathrm{N}^{\circ} 02$ no muestra indicios de verse influenciada por los principios de la cultura empresarial, como se pensaba en un planteamiento inicial; es decir, una cultura que exalta las tres bases del éxito empresarial: eficiencia, eficacia y efectividad ${ }^{6}$. Por tanto, esto robustece la idea de que la institución educativa se presenta como un bastión de resistencia frente a este tipo de influencia en el mundo educativo, pues contiene diversas características que Armengol (en Páez et al., 2004) identifica en sus tipologías culturales de la enseñanza como «cultura de la organización» $\mathrm{y}$ «cultura colaborativa».

\footnotetext{
6 Esto también alude a un uso indiscriminado de la maximización de recursos limitados con una noción absoluta utilitarista.
} 
En relación con el manejo del cambio institucional, una de las fortalezas identificadas en la I.E. Fe y Alegría $\mathrm{N}^{\circ} 02$ fue la constante percepción de adecuación entre los entrevistados. Al respecto, la institución había innovado en el plano organizacional ańos atrás por medio de la aplicación de un conjunto de medidas: (i) la nueva programación curricular Doble T de Martiniano; (ii) la capacitación de personal docente, y (iii) la codificación de los miembros de la Asociación de Padres de Familia (APAFA). Asimismo, la institución tiene una vieja tradición de generar un espacio de diálogo para mitigar posibles focos de conflicto. Esto, sin duda, contribuye a procesos de cambio institucional en distintos momentos del desarrollo histórico de la institución educativa.

Enseguida, se indica que la búsqueda de nuevos programas educativos resulta importante para el desarrollo de los estudiantes y la satisfacción de sus necesidades:

En el 80, lo que se valoraba bastante fue la organización. En el 90, ya más bien hubo el trabajo y el proyecto de búsqueda de tener, diríamos, competencias sostenibles, de acuerdo a lo nuevo. [...] Estábamos en la búsqueda de lo que es lo mejor para que los chicos se desarrollen, que respondan a las necesidades. Por eso, uno de nosotros llegó hasta la programación Doble T de Martiniano, que era/es un catedrático español que lo diseñó [...] el ministerio [MINEDU] después lo llamó (docente de Ciencias Sociales desde la década de 1980 hasta la actualidad y subdirectora de Formación General en 2017. Comunicación personal, 3 de noviembre de 2017).

Además, se señala que la preservación de la "mística Fe y Alegría» ocurría mediante la constante búsqueda de la unión entre sus agentes, como la capacitación uniforme de todos sus profesores:

A pesar de que en el colegio han pasado cuatro directoras, cada una con diferentes características, siempre mantenían la «mística de Fe y Alegría» de mantenernos a todos unidos. De manera uniforme, todos debíamos estar capacitados [...] se preocupaban bastante en eso. [...] Nos ayudaban. Entonces, con qué ganas uno va a dejar este colegio si se preocupan por uno. Por eso, he seguido aquí (docente de Educación para el Trabajo de la especialidad de Confecciones Industriales desde la década de 1980 hasta 2018. Comunicación personal, 8 de febrero de 2018).

Aparte de ello, se afirma que la codificación de los padres de familia ayuda a fiscalizar la participación en las actividades del plantel:

Mire, los padres de familia tienen un código, tienen una tarjeta ahí donde está el control de las actividades. Entonces, en esa tarjeta están codificados. A cada padre le corresponde un estudiante. [...] de acuerdo con esos códigos, les van haciendo los roles de las faenas (docente de educación primaria desde la década de 1990 hasta la actualidad y subdirectora de educación primaria en 2017. Comunicación personal, 20 de octubre de 2017). 
Como queda en evidencia, el plantel ha desarrollado múltiples formas de comunicación entre sus miembros, así también ha generado y desarrollado liderazgos en diferentes instancias de gestión (dentro del aula, entre padres de familia, entre coordinadores, etc.). Adicionalmente, la evidencia señala que la I.E. Fe y Alegría $\mathrm{N}^{\circ}$ 02, más que llevar a cabo un proceso de contextualización, ha trasmitido de forma no violenta su cultura organizacional. Así, ella ha generado nuevos hábitos y conseguido que los prestatarios de su servicio educativo se adecuen a sus prácticas y premisas institucionales. Parte de esta nueva cultura trasmite un discurso de insatisfacción entre los diferentes grupos que conforman la comunidad educativa; es decir, mejorar lo hecho o lo dado considerando las propias habilidades, competencias y limitaciones.

A continuación, se muestra que la orientación a las familias ocurre a través de charlas de consejería dentro del plantel:

Como le mencionaba, también me parece muy importante lo que aportan los profesores en el comité de aula, que den charlas de consejería, "Qué bueno amor y límites», se llama. El año pasado también lo llevé con mi hijo. Este año lo llevo con mi otro hijo. Él lo reclama. Mi esposo es otra persona (madre de familia en 2017, comunicación personal, 3 de noviembre de 2017).

Como se recuerda, el nuevo institucionalismo hace fluctuar a la cultura organizacional entre una cultura basada en la confianza y el autocontrol y otra basada en la desconfianza y el control externo. Con relación a dicho escenario binario, la I.E. Fe y Alegría $\mathrm{N}^{\circ} 02$ ha logrado acoplarse a un clima de confianza y control no solo externo, sino también interno (autocontrol). Dicho logro ha sido posible solo en la medida de que el plantel ha dotado a todos sus miembros de una función supervisora y de acompañamiento («una cultura del acompañamiento»).

En seguida, se señala que el alto compromiso educativo resulta capital para los estudiantes:

Tú vas a dar más de lo que te van a pagar. No es que yo trabajo por mis horas y me voy al término. No es así. Hay muchas cosas que hacer aquí en el colegio, de ser tutora, porque con los alumnos, yo que soy de la promoción, ves sus sueños, sus esperanzas, sus proyectos (docente de la especialidad de Psicología y Filosofía durante la década de 1990 y coordinadora del Comité Gestión de Tutoría desde 2007 hasta 2017. Comunicación personal, 20 de noviembre de 2017).

También se especifica que el liderazgo implica acompañamiento, apoyo y perseverancia:

En torno al liderazgo, yo creo que tienen que apoyar mucho las personas de su trabajo, su equipo. No siempre se tiene que estar adelante, sino al costado 
de ellos: ayudándolos a seguir un buen camino, siendo transparente también, diciendo las cosas como son, qué es lo que falta, sin tener miedo a nada (alcaldesa del municipio escolar en 2017. Comunicación personal, 30 de octubre de 2017).

Asimismo, se hace mención que el control a los padres de familia ocurre muchas veces mediante sanciones:

Los padres, aquí, ahora, se están manejando con lista. Vienen a una reunión, vienen a una escuela de padre; el padre que no asiste, paga su multa. Ahora, como se dice, el papá debe ser responsable, y hay algunos que se quieren pasar de vivos. [...] En los 80 no había escuela de padres, solo había la Asamblea General [...] se pagaba con un trabajo. Ahora es multa (madre de familia integrante de la APAFA en 2017. Comunicación personal, 30 de octubre de 2017).

El acoplamiento también se da hacia los nuevos sistemas educativos observados por la I.E. Fe y Alegría Nº2 como referentes. Por ejemplo, el modelo de educación europeo, del cual es heredera la exdirectora Julia Martínez. En cada uno de los períodos estudiados, los referentes son fijados por sus autoridades del momento, quienes no solo tienen una función administrativa, sino además se encargan de pensar e imaginar la escuela en el futuro.

A continuación, se rememora a la exdirectora Julia Martínez, figura clave para la I.E. Fe y Alegría Nº2:

Julia Martínez, esa hermana inteligente, europea. [...] Ella es una persona leída. [...] En ese tiempo, era profesora, pero venía de ser directora de la I. E. Fe y Alegría $\mathrm{N}^{\circ}$ 24. Acá llegó como una profesora más [...] ella venía de la zona de Tablada, de Villa El Salvador. Salieron al frente y lucharon por sus derechos, también trataron a senderos [senderistas], y también defendieron a la iglesia al lado de su pueblo (docente de Ciencias Sociales desde la década de 1980 hasta la década actual y subdirectora de Formación General en 2017. Comunicación personal, 3 de noviembre de 2017).

La cita anterior ayuda a observar un fenómeno de acoplamiento técnico, donde ciertas reglas y personalidades han sido convertidas en mitos. Dicha mitificación alude a la transformación de ciertos personajes/cosas/procesos en referentes o modelos a seguir para la cultura organizacional. En función de ello, se legitima la necesidad de cambio o constancia dentro de la I.E. Fe y Alegría Nº2. Entre los ejemplos más representativos de mitificación se tiene el caso de la exdirectora Julia Martínez, la Doble $\mathrm{T}$ de Martiniano, las madres de familia y el ideario. En esa medida, lo que la institución educativa entiende como "la mística Fe y Alegría», en el fondo hace referencia a una apuesta por mitificar reglas o figuras históricas. Ello ha influenciado sobre su sistema de gestión institucional y legitima la toma de acciones y la autoridad. 


\section{Resultados del espacio participativo}

En retrospectiva, el caso de la I.E. Fe y Alegría $N^{\circ} 02$ confirma la existencia de diferentes niveles de acoplamiento ${ }^{7}$ en su interior. Bajo los resultados de la presente investigación, el acoplamiento se da en los diferentes espacios participativos: físico, mental, social y pedagógico. Cada uno de ellos contribuye a los diversos actores para apropiarse, reproducir, socializar e instruirse en diferentes materias y, de esa manera, adecuarse a los cambios que requiere todo proceso de acoplamiento, como se puede observar en las secciones alusivas a la cultura organizacional y gestión educativa. En seguida, se presentan algunas pistas que permiten esclarecer lo mencionado.

\section{Resultados del espacio participativo físico}

Según Lefebvre (1976), el espacio tiene multiplicidad de formas. Lo que se entenderá por "espacio físico» hace referencia al «espacio percibido-sensible-físico», esto es, el espacio es analizado en tanto produce y reproduce lugares específicos, tipologías y jerarquías sociales específicas. En el ámbito educativo, lo anterior sugiere abordar el análisis de la participación considerando los tres aspectos esenciales de esta categoría. A continuación, se dan algunas menciones importantes sobre los espacios físicos aludidos por los entrevistados en el plantel, lo cual permitirá observar su funcionamiento, su cambio y la interacción de los actores en torno la institución.

Con respecto a las tómbolas, se apunta: «Las tómbolas son para generar los recursos. El padre venía y colaboraba con productos. La oficina mandaba productos y se hacían las tómbolas. Ya no se hacen las tómbolas como antes» (docente de Educación para el Trabajo de la espacialidad de Confecciones Industriales desde la década de 1980 hasta 2018. Comunicación personal, 8 de febrero de 2018).

En relación con el bingo, se señala:

Había muy pocas reuniones. Siempre había reuniones con padres de familia y con nuestras especialidades. [...] Antes, había bingos con fiesta, con castillo; [...] ahora, los bingos son organizados por las promociones. Eso todavía hay. Pero ya no es como antes. Antes había fiesta (docente de Educación para el Trabajo de la espacialidad de Ciencias Comerciales desde la década de 1980 hasta 2018. Comunicación personal, 8 de febrero de 2018).

A propósito de los eventos festivos, se menciona:

Actualmente, hay varias reuniones que son escuela de padres. Las reuniones de APAFA que hay. Los aniversarios. Cuando hay aniversarios. Los eventos que se realizan como las festidanzas. Feria gastronómica. [...] Hay bingos. La kermés

\footnotetext{
No se dan necesariamente de manera secuencial en la institución educativa.
} 
el año pasado no ha habido [...] hay cosas que han cambiado, pero para bien (estudiante de la década de 1970 y madre de familia durante la década de 1990. Comunicación personal, 8 de febrero de 2018).

Acerca de la reunión general de la APAFA, se indica:

La reunión general de la APAFA se realiza en la losa de la institución educativa y la directiva tiene un salón asignado al constado de Qali Warma, dentro de la institución educativa. [...] Se ve el balance, los padres opinan, hacen pedidos, ven si se gasta más de la cuenta y fiscalizan si desean (presidenta de la APAFA durante la década actual. Comunicación personal, 30 de octubre de 2017).

En cuanto a la sala de líderes, se señala: "La sala de líderes es donde se planean ideas con el municipio escolar y se da detalladamente el plan de trabajo con el objetivo de poder realizarlo y ejecutarlo en la institución educativa» (alcaldesa del municipio escolar en 2017, comunicación personal, 30 de octubre de 2017).

Sobre las reuniones entre docentes y padres de familia, se alude:

El maestro interviene como un medio para poder hacer viable esas reuniones. Ya ahora el profesor sabe que, antes de esas reuniones, nosotros tenemos que regresar en la noche para reuniones de padres, porque estas reuniones tienen que ser cuando el padre esté. Nosotros ya sabemos ver eso (docente y coordinador académico de la especialidad de Matemática en 2018. Comunicación personal, 7 de febrero de 2018).

A partir de las citas anteriores, se pudo constatar lo siguiente: (i) cada uno de los actores educativos tiene una alta valoración por las organizaciones y actividades más próximas a su actividad cotidiana; (ii) las reuniones con las familias (especialmente, con las madres) se han mantenido en el tiempo, a pesar de que las formas y las dinámicas en ellas hayan cambiado; (iii) actualmente, un mayor número de actividades recreativas y festivas significa un mayor número de puntos de encuentro dentro del plantel; (iv) cada actor y grupo se apropia de diferentes espacios dentro de la escuela, lo que resulta ser una constante desde los inicios de la institución educativa; (v) todos los actores educativos del plantel declaran que tienen un lugar y reconocen el espacio que ocupa el otro; (vi) la institución educativa persiste en acondicionar ciertos espacios en el plantel para cumplir una función pedagógica; no obstante, surgen algunas voces entre los docentes que piden generar espacios más exclusivos para la práctica de ciertas actividades; (vii) existe una tarea constante por generar perfiles con capacidad de liderazgo; (viii) para convocar a la comunidad en el presente, se utilizan instrumentos distintos a los usados décadas atrás (antes, comunicados o volantes; hoy, la agenda de asistencia de los estudiantes o medios tecnológicos), y (ix) hay cambios en la forma de canalizar las demandas del estudiante (antes se canalizaban de forma directa; hoy se canalizan a través de intermediarios). 


\section{Resultados del espacio participativo mental}

Volviendo otra vez a Lefebvre (1976), el «espacio mental» se relaciona con los discursos acerca del espacio. Bajo esta estructura, lo dominante son los signos, los códigos y las relaciones frontales. En el ámbito educativo, estos tres elementos quedan plasmados en todo aquel documento escrito, el cual funciona como un marco normativo que dirige el actuar de los actores educativos o el funcionamiento del plantel. Al respecto, veamos algunas citas que dan luces de lo expuesto.

En seguida, se menciona que la comunicación oral es la base del intercambio de información:

En ese entonces [década de 1980], no había textos. No tantos les daban a los niños. La comunicación y la guía se daban en diálogo, de forma oral. Había bastante comunicación (madre de familia durante la década de 1980. Comunicación personal, 15 de febrero de 2018).

Luego, se acota que los extractos de la propuesta educativa del padre Usera representan la base de la discusión y programación educacional:

Se establecían ciertas pautas de lo que es el trabajo de Fe y Alegría en el Perú. Nosotros discutíamos y conversábamos para tenerlo en cuenta, programar y hacer nuestro trabajo. Luego, la congregación nos hacía llegar unos extractos de lo que el padre Usera, el mentor de ellas, concebía como la educación que sería impartida a los más pobres (madre de familia durante la década de 1980. Comunicación personal, 15 de febrero de 2018).

Asimismo, se señala que los fólderes de los delegados de disciplina son la base del sistema de control aplicado para los estudiantes:

A nosotros, los delegados de disciplina, nos entregan un fólder. Ahí trabajan todos los delegados: aseo, asistencia y disciplina. Disciplina [...] lo que hacemos nosotros es hacer firmar a cada profesor el parte y anotar a los alumnos que se comportan mal, qué ha hecho. Atrás del fólder está la función que tiene cada delegado (estudiante delegado del aula durante la década actual. Comunicación personal, 30 de octubre de 2017)

Las citas anteriores solo son una parte del total de entrevistas hechas sobre este tópico. Sin embargo, sumándolas al análisis del conjunto, se puede señalar lo siguiente: (i) los textos especializados en materia educativa son elaborados y entregados por órganos de la propia institución y el MINEDU (su contenido es básicamente conocido por aquellos actores que tienen o han tenido una responsabilidad directiva en el plantel); (ii) décadas atrás, informar a los padres y madres sobre sus responsabilidades no requería ningún tipo de texto, pues toda esta transferencia de conocimiento e información se realizaba oralmente a través del diálogo con una 
autoridad del plantel o un padre con experiencia previa en el cargo (actualmente, se plasma en el reglamento interno y otros); (iii) los documentos religiosos (por ejemplo, el texto Proyecto de Pastoral Juvenil Vocacional) no se han posicionado de forma contundente en el discurso cotidiano de la mayoría de los entrevistados (no obstante, sus lineamientos guían el rumbo de la gestión y de la pedagogía dentro del plantel de manera general); (iv) a diferencia de décadas pasadas, la congregación ha visto la necesidad de elaborar un material que guía toda acción e intervención educativa presente y futura; (v) hay indicios de un proceso de sistematización y racionalización de los instrumentos de la fe para abordar desafíos educativos actuales, y (vi) hay documentos que no necesitan ser impresos (por ejemplo, el ideario), pues todo lo consignado en ellos está en la consciencia de los docentes más antiguos del plantel y ellos lo trasmiten a las siguientes generaciones de docentes.

\section{Resultados del espacio participativo social}

Un tercer tipo de espacio es el «espacio social», entendido por Lefebvre (1976) como «espacio vivido-relacional-social». Este ofrece una región de alternativas complejamente codificadas, decodificadas o recodificadas, utilizadas como resistencia simbólica (dimensión clandestina y subterránea de la vida social). Al respecto, este tipo de espacio sugiere reestructuraciones alternativas y revolucionarias de las presentaciones institucionalizadas del espacio y nuevas modalidades de prácticas espaciales. En el ámbito educativo, esto implica profundizar sobre aquellos nexos o vínculos que la institución y sus actores establecen con grupos foráneos o grupos aliados e, incluso, aquellos vínculos generados en espacios alternos o no oficiales. Para mayor ejemplificación de este punto, las siguientes citas pueden dar mayores alcances.

A continuación, se hace mención de que en la década de 1980 hubo autoayuda y autoabastecimiento:

Las hermanas hicieron un club de madres de familia, donde la hermana Sara nos enseñaba a cocinar. Nos orientaba a cómo cocinar en la comunidad, sin mucho gasto $[\ldots]$ nos enseñaba en el comedor, dentro de Fe y Alegría. En los ochenta, ya no había eso. En ese entonces, también se turnaban para ir al jardín y cocinar. Esa organización era como parte del club de madres. [...] En ese entonces, no había ONG. Había donaciones, pero no sé de dónde (madre de familia durante la década de los ochenta. Comunicación personal, 15 de febrero de 2018).

Luego, se apunta que existieron los primeros contactos de la I.E. Fe y Alegría $\mathrm{N}^{\circ}$ 02 con instituciones del Estado durante la década de 1990:

Yo solo sé que CEDRO vino en los noventa. Daba charlas sobre drogas. Luego, había instrucción premilitar. Nos castigaban por llegar tarde. Este era un curso. Todo el mundo no quería dar vueltas, ranas, saltos. Los alumnos tenían que tener 
bien cortaditos sus cabellos (estudiante durante la década de 1990 y madre de familia en 2018. Comunicación personal, 13 de febrero de 2018).

Posteriormente, se menciona que las instituciones privadas y las universidades se pliegan a la I.E. Fe y Alegría Nº2 a partir de la década de 2000:

Este tipo de trabajo con aliados [universidades, entidades públicas o instituciones privadas diversas] se hace presente recién a partir de los 2000 en adelante y se asocia al hecho de que la institución educativa se hace conocida (docente y coordinador académico de la especialidad de Matemática en 2018. Comunicación personal, 7 de febrero de 2018).

Por último, se indica que actualmente la I.E. Fe y Alegría $\mathrm{N}^{\circ} 02$ ha fortalecido sus vínculos con las universidades, instituciones del Estado y entidades financieras:

Las instituciones sí han participado, como la Católica y la Cayetano, que los chicos les dan la oportunidad de poder, en cuanto a su salud, hacer la profilaxis y, en cuanto a sus estudios, la Católica les abre las puertas para que puedan seguir estudios superiores. DEVIDA intervino hace tres o dos ańos (docente de educación secundaria especialidad de Matemática y Física desde la década de 1990 hasta 2018. Comunicación personal, 7 de febrero de 2018).

De las citas anteriores, se observaron los siguientes resultados: (i) la ayuda o apoyo a la I.E. se ha dado de manera progresiva desde la década de 1990; (ii) hay un grato recuerdo de varias universidades que implementaron proyectos de apoyo en diferentes temáticas; (iii) hasta la década de 1980, existe una memoria de clubes de madre liderados por las hermanas del plantel, que funcionaban como un soporte técnico e instrucción para las mujeres de la comunidades en labores de su cotidianidad.

\section{Resultados del espacio participativo pedagógico}

Como bien señala Bourdieu (1996), el sistema escolar internaliza, reproduce un habitus y transforma desigualdades sociales en desigualdades naturales. Esto lo hace a través de un ejercicio de legitimación de las relaciones sociales (violencia simbólica). Al respecto, Bourdieu indica que la legitimización solo es posible gracias a una acción pedagógica que influya sobre la personalidad de los actores educativos (o individuos). Medir dicha acción implica tomar en cuenta el grado de duración del habitus inculcado, la medida en que el habitus es transferible y la exhaustividad del habitus. Ante lo mencionado, el «espacio pedagógico» será todo espacio de instrucción donde las dinámicas entre los sujetos respondan al fin de transferir un tipo de conocimiento en particular, para lo cual se disponen múltiples estrategias, por ejemplo, el control, la represión, el uso de la fuerza, la motivación, entre otros. 
Seguidamente, se reflexiona en torno a la severidad de los castigos:

La profesora que yo tuve en primaria era bien recta. Entonces, cuando había problemas, de frente a la patilla. [...] Por ejemplo, recuerdo a un profesor de historia [...] chico que no cumplía con su tarea, no escuchaba en clase o distraía a sus compańeros, los hacia arrodillar en chapitas (estudiante durante la década de 1980 y auxiliar de educación destacada en la biblioteca del plantel en 2017. Comunicación personal, 20 de noviembre de 2017).

Aparte de ello, se hace mención al consenso y a la delegación de responsabilidades:

Es la parte del consenso, es la parte consensual del trabajo con los chicos [...] se alterna el trabajo en colectivo y el dar responsabilidad. Se llevan a cabo como acuerdos en conjunto, de acuerdo al aula. Se dan compromisos internamente y tareas. Se delegan tareas (docente y coordinadora académica de Arte en 2017. Comunicación personal, 20 de noviembre de 2017).

Asimismo, se alude a la innovación constante en las estrategias de trabajo:

Se van cambiando siempre las estrategias, porque no siempre van a trabajar en equipo. Es una de las cosas que diferimos con el Ministerio. Plantean todo en grupo, no nos parece adecuado, no siempre. Es importante, sí, pero no siempre, porque toda estrategia que es repetitiva cansa, toda estrategia repetitiva no produce (docente y coordinador académico de la especialidad de Matemática en 2018. Comunicación personal, 7 de febrero de 2018).

Finalmente, se hace referencia a la rotación de los estudiantes y el trabajo grupal:

Ya uno como padre está apoyando. Ahí, entonces, grupalmente ha aprendido [su hija] a desenvolverse sola, ha aprendido a ser más independiente, más organizada. [...] aquí cambian todos los años. Rotan los niños y todos son amigos y ahora ya no hay desconfianza con todos (madre de familia miembro del comité de vigilancia en 2017. Comunicación personal, 30 de octubre de 2017).

Entre los hallazgos más resaltantes, se pueden señalar los siguientes: (i) no se percibió un consenso entre los entrevistados sobre la existencia de prácticas participativas dentro de la institución en la década de los 80; (ii) hay voces discrepantes en cuanto a la presencia o la aplicación de prácticas o dinámicas participativas dentro del plantel; (iii) los docentes señalan que la consigna de fomentar la participación dentro del aula, según el Minedu, debe ser tomada con reflexión: en algunos casos, resulta necesario; y, en otros casos, no es pertinente; (iv) hay cierto consenso entre las madres con respecto a que las prácticas participativas ayudan a desarrollar habilidades sociales en los estudiantes; (v) la totalidad de los actores educativos entrevistados concuerdan con la idea de incorporar elementos participativos en la resolución de conflictos en el aula; (vi) el manejo del conflicto en el plantel se basa 
en la búsqueda de consensos; en la década de 1980, esto implicaba correcciones físicas (violencia física) sobre los estudiantes, y (vii) actualmente, el conflicto se maneja en un clima de democracia.

\section{Resultados de la gestión educativa}

Como se indicó en el marco teórico, el acoplamiento técnico tiene, en el fondo, un poder homogeneizador. Para lograr esta homogenización, resulta indispensable el ejercicio del poder entendido como control. En un primer nivel de acoplamiento, el Estado, en su reforma de política educativa, inmerso actualmente en una política de homogenizar procesos de gestión escolar (currículo nacional), intenta que las instituciones educativas se manejen en función de un solo marco de programación curricular. Incorporar esto para la I.E. Fe y Alegría $N^{\circ} 02$, que basa su progreso en la innovación constante, significa abandonar uno de sus principios de éxito. En este punto, cabe preguntar si el sistema educativo peruano deja márgenes de innovación para la institución educativa.

Seguidamente, se apunta que las disposiciones homogeneizadoras del Minedu pueden llegar a ser un obstáculo para una institución educativa que basa su éxito en la innovación, la autoformación y la autorreforma:

En la parte pedagógica, uno tiene la convicción de que puede aportar de acuerdo a nuestra realidad, o sea, nosotros nos autoformamos. Estamos acostumbrados a reunirnos permanentemente. Ir analizando toda la marcha institucional [...] Sin embargo, algo que no nos está ayudando es la misma política educativa. No nos permite avanzar más (docente y coordinador académico de la especialidad de Matemática en 2018. Comunicación personal, 7 de febrero de 2018).

El segundo nivel de acoplamiento es el grado de acción que tienen los actores para cumplir sus labores sin obstruirse entre ellos. Como se llegó a mostrar, cada actor educativo, de forma individual o colectiva, tiene un espacio que utilizar dentro de la institución. En tal sentido, la I.E. muestra un adecuado manejo de los espacios y de los tiempos. Ello ha sido una constante a lo largo de los años. Al respecto, los espacios no son exclusivamente para la reunión de un grupo en particular, sino para buscar una interacción entre todos los actores dentro de ellos. Esto es, el padre habla con el docente, el docente con los alumnos, los directivos con los padres de familia, entre otros acercamientos. Todo eso no sería posible si no existiera un reglamento interno que estipule de manera clara y general los límites de los marcos de acción para cada uno de los actores educativos.

A continuación, se sugiere la necesidad de menos sanciones y más acompañamiento interno e institucional: 
Más que una sanción, es importante poner énfasis en el acompañamiento, dos tipos: el acompañamiento institucional, es decir, el monitor de Fe y Alegría visita el colegio, y el acompañamiento interno. Son pocas las sanciones. Mayormente, se excusan los involucrados. Los profesores se encargan de avisar (docente de educación primaria desde la década de 1990 hasta la década actual y subdirectora de educación primaria en 2017. Comunicación personal, 20 de octubre de 2017).

Asimismo, se señala la manera de gestionar las áreas de trabajo dentro de la institución educativa:

En la coordinación de matemática, sí nos hemos adueñado de la sala de profesores. Lo que pasa es que los profesores tienen hora libre y, como no ven reuniones, como somos mayoría, entonces utilizamos el espacio [...] como la mesa es larga, se tiende a decir: «Ustedes vayan para allá, nosotros para acá» (docente y coordinador académico de la especialidad de Matemática en 2018. Comunicación personal, 7 de febrero de 2018).

En un tercer nivel de acoplamiento, se indaga sobre cuánto de la praxis de los actores confluye con los esquemas formales de su función estipulados en el reglamento interno. Según lo observado, se confirma un alto grado de naturalización de los marcos de intervención destinados a los actores. El ideario es un buen ejemplo de esto. Dicho documento, que inicialmente era físico, en la actualidad ya no es utilizado por los docentes, pues su contenido ya ha sido incorporado a su praxis. Lo que demuestra ello es que ciertos actores ya poseen un habitus de trabajo. Los actores más antiguos son los que, en mayor medida, muestran dicho habitus (padres y madres de familia que han sido estudiantes o docentes, quienes trabajan muchas décadas en la institución educativa). Dicho grupo de actores, en muchos casos, también representan un elemento de coerción social, pues realizan la tarea de alinear a los nuevos integrantes para adoptar prácticas estipuladas en el reglamento interno. Si bien ellos infringen un tipo de coerción indirecta y pasiva, brindan además motivación y respaldo.

En seguida, se acota que, con la modernidad, ya no se utiliza el ideario, porque los profesores han incorporado esa teoría en su práctica:

Con la modernidad, ya no se utiliza el ideario, porque los profesores ya han incorporado lo que decía en él en su práctica. [...] nosotros tenemos noción del ideario, pero ahorita que nos preguntas, estamos cayendo en cuenta que ya más de medio colegio no tiene noción de eso (docente de educación secundaria de la especialidad de Matemática y Física desde la década de 1990 hasta el 2018. Comunicación personal, 7 de febrero de 2018).

El último nivel de acoplamiento es el grado de autosujeción, desarrollado por los actores educativos para cumplir con la función demandada. En este nivel de 
acoplamiento, surgen varias interrogantes a tomar en consideración. Por ejemplo, ¿por qué los actores cumplen con sus deberes? ¿Cuáles son sus motivaciones? ¿Qué encuentran en la I.E. Fe y Alegría $\mathrm{N}^{\circ} 02$ que no hay en otras instituciones educativas?

Por la información procesada, se observa que los actores se convencen de lo que hacen y lo realizan por dos elementos propios de la institución educativa. Uno de ellos es el clima en el cual se enmarca su trabajo y la motivación para encausar sus acciones. Sobre tales aspectos, los actores educativos refieren la existencia de un ambiente de familiaridad, de confianza, de seguridad, donde su voz es tomada en cuenta, pueden participar y, además, son supervisados y asesorados (ver anexo, cuadro 4).

El segundo elemento es la implementación de un trabajo de concientización muy fuerte de la institución entre sus miembros. Esto es algo constante en los períodos de análisis estudiados. Parte del trabajo de concientización lo realiza el propio plantel. Otra gran parte de este trabajo la realizan —en paralelo- sus miembros más antiguos. En particular, tal proceso de concientización se puede apreciar con mayor claridad en todos los aspectos que reconocen los entrevistados como fortalezas del plantel de la I.E. Fe y Alegría $\mathrm{N}^{\circ} 02$ en cada período de análisis (ver anexo, cuadro 5).

\section{CONCLUSIONES Y RETOS FUTUROS}

En primer lugar, se concluye que los procesos de racionalización y mitificación son esenciales para la convergencia de sistemas distintos temporalmente; la construcción de una sola identidad institucional, y la legitimidad de las decisiones y la autoridad. Sin embargo, aún queda espacio para ahondar sobre lo identificado como "proceso de mitificación». Vale preguntarse entonces: (i) ¿requiere el proceso de racionalización en la gestión institucional un análisis más amplio? (ii) ¿̇las características de este proceso son únicas según el plantel educativo intervenido?

En segundo lugar, se sostiene que un acoplamiento exitoso necesita la creación de diferentes espacios participativos (físico, mental, social y pedagógico) y la práctica de dinámicas participativas dentro de sus diferentes niveles. Así también es claro que las dinámicas participativas cambian, pero aquellas que persisten se adaptan a marcos contemporáneos. Con lo expuesto, se devela la heterogeneidad de la realidad institucional de los colegios de la red Fe y Alegría y ello da como resultado dos interrogantes: (i) ¿son los procesos de acoplamiento técnico e institucional elementos sustanciales para entender el perfomance de las escuelas? (ii) ¿se puede elaborar una metodología cuantitativa para ver esta evolución?

Finalmente, se determina que la cultura organizacional, tanto su cultura de tránsito como su cultura mitificada, transmite consignas ético/morales y una praxis 
sobre la gestión educativa y los espacios de participación. En el contexto actual, dado el auge por incorporar la participación en modelos de gestión escolar, es impostergable cuestionar: (i) ¿es la participación valorada realmente en los espacios de gestión? (ii) ¿cuáles son sus limitaciones y posibilidades? (iii) ¿es eficaz o necesita una revaluación?

\section{REFERENCIAS}

Barrientos, A. \& Taracena, E. (2008). La participación y estilos de gestión escolar de directores de secundaria: un estudio de caso. RMIE, 13(36), 113-141. Recuperado de http://www.scielo.org.mx/pdf/rmie/v13n36/v13n36a6.pdf

Bourdieu, P. \& Passeron, J. (1996). La reproducción: elementos para una teoría del sistema de enseñanza. México D.F.: Distribuciones Fontamara.

Eguren, M. (2006). Revisión de la literatura. En C. Montero (ed.), Escuela y participación en el Perú. Temas y dilemas (pp. 29-49). Lima: IEP.

Gamorran, A. \& Dreeben, R. (1986). Coupling and control in educational organizations. Johnson Graduate School of Management, Cornell University. Administrative Science Quarterly, 31(4), pp. 612-632. https://doi.org/10.2307/2392966

Garmendia, J. (2006). La cultura de la empresa. En P. Bobadilla (comp.), Desarrollo organizacional en las $O N G$, (pp. 285-302). Lima: PACT/Perú.

Gento, S. (1996). Participación en la gestión educativa. Madrid: Santillana.

Gómez, L. (1994). La cultura de la empresa. En A. Marín (ed.), Sociología para la empresa, (pp.131-153). Madrid: McGraw Hill.

Hernández, R. (2009). Prácticas prometedoras de desempeño institucional asociadas al nivel de logro académico de las escuelas. Lecciones desde escuelas secundarias con mejores niveles de rendimiento en el Estado de Chihuahua. En X Congreso Nacional de Investigación Educativa, Veracruz.

Incio, N. (2015). Sentido subjetivo de la participación de madres y padres en la institución educativa $N^{\circ} 58$ Mary Ward (tesis de maestría en Psicología Comunitaria). Lima: Pontificia Universidad Católica del Perú.

Lavado, P., S. Cueto, G. Yamada y M. Wensjoe (2014). El efecto de Fe y Alegría sobre el desempeño escolar en segundo de primaria: explorando el sorteo en el ingreso como experimento natural. Lima: Universidad del Pacífico y Grupo de Análisis para el Desarrollo, documento de discusión DD1407.

Lefebvre, H. (1976). Espacio y politica. Barcelona: Península.

Meyer, J. y B. Rowan (1977). Institutionalized Organisations: Formal Structure as Myth and Ceremony. The American Journal of Sociology, 83(2), 340-363. https://doi. org/10.1086/226550

Páez, D. \& Zubieta, E. (2004). Cultura y psicología social. En D. Páez, I. Fernández, S. Ubillos y E. Zubieta (coords.), Psicología social, cultural y educación (pp. 25-44). Madrid: Pearson Prentice Hall. 
Parra,J.\&Wodon,Q.(2011).EscuelasreligiosasenAméricaLatina:estudiosdecasosobreFeyAlegría. Recuperadodehttp://documents.worldbank.org/curated/en/141061468331809734/ Escuelas-religiosas-en-America-Latina-estudios-de-caso-sobre-Fe-y-Alegr-237-a

Sánchez, J. (2013). Participación educativa y mediación escolar: una nueva concepción en la escuela del siglo XXI. Aposta. Revista de Ciencias Sociales, (59), 1-28. Recuperado de http://apostadigital.com/revistav3/hemeroteca/jfcanovas2.pdf

Santizo, C. (2011). Gobernanza y participación social en la escuela pública. Revista Mexicana de Investigación Educativa (RMIE), 16(50), pp. 751-773. Recuperado de http:// www.redalyc.org/pdf/140/14019000005.pdf

Stojnic, L. y N. Consiglieri (2016). Ser escuela, construir comunidad: factores de éxito del modelo de gestión Fe y Alegría. Recuperado de http://dars.pucp.edu.pe/publicacion/ escuela-construir-comunidad-factores-exito-del-modelo-gestion-fe-alegria/

Trujillo, C. (2019). Los cambios en la cultura organizacional y sus influencias sobre el desempeño institucional: un análisis a los cambios experimentados por la Institución Educativa $2009 \mathrm{Fe}$ y Alegría $n^{\circ} 02$ (tesis de licenciatura). Pontificia Universidad Católica del Perú.

Yuli, M., D. Sosa y R. Araya (2004). Escuelas experimentales autogestionadas. Participación de los padres. San Luis. Revista Mexicana de Investigación Educativa (RMIE) Fundamentos en Humanidades, 5(10), 99-130. Recuperado de http://www.redalyc.org/ articulo.oa?id $=18401006$

Weick, K. (2004). Educational Organizational as Loosely Coupled Systems. Adminitrative Science Quarterly, 21(1), 1-19. https://doi.org/10.2307/2391875

Zimmermann, A. (2000). Gestión del cambio organizacional: caminos y herramientas. Recuperado de http://www.academia.edu/22780044/GESTI\%C3\%93N_DEL_ CAMBIO_ORGANIZACIONAL_CAMINOS_Y_HERRAMIENTAS 


\section{Anexo}

Tabla 3. Principios de la propuesta de gestión en la I.E. Fe y Alegría Nº 02 por período de análisis según PEI

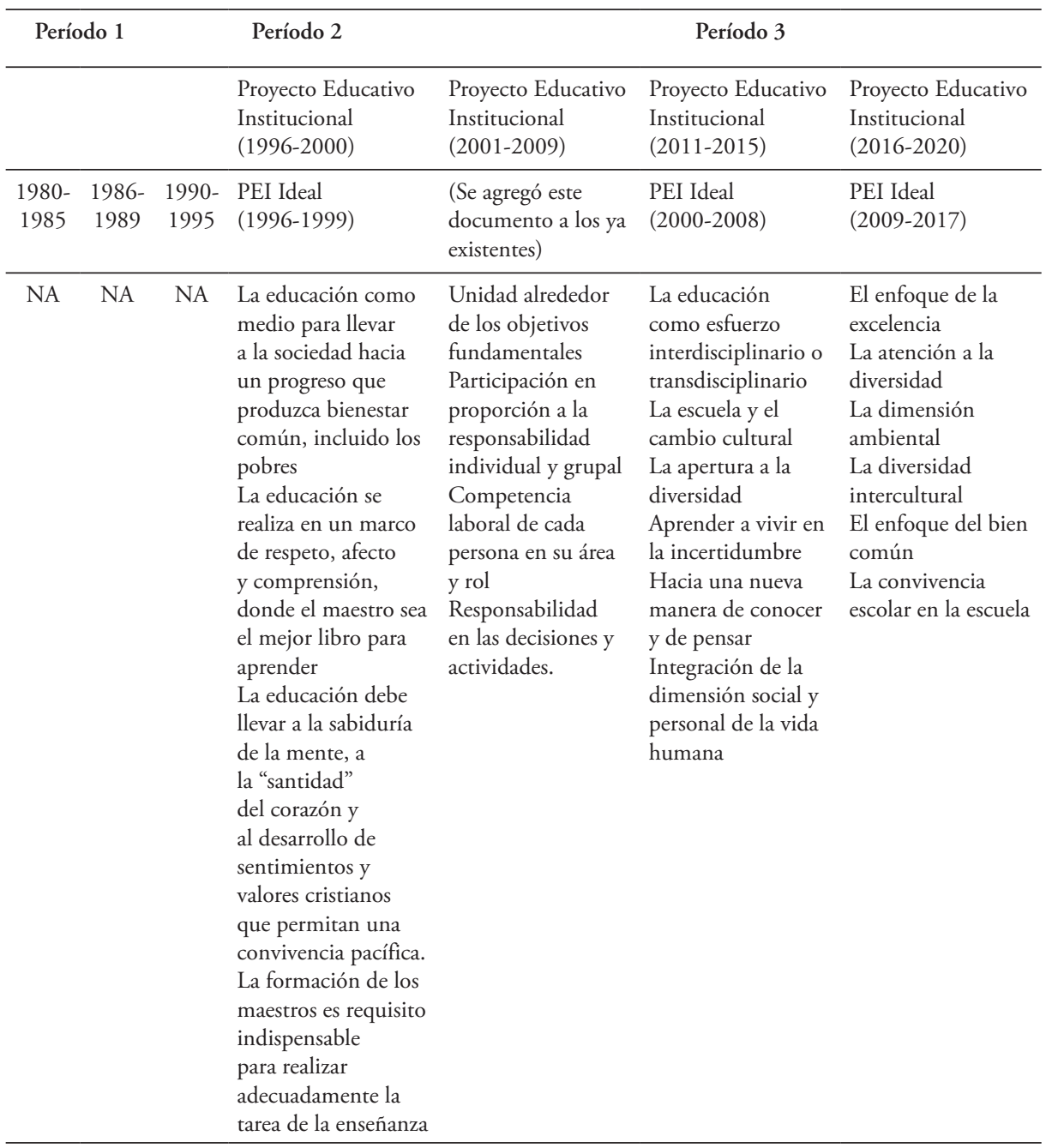




\section{Tabla 4. Tipo de motivaciones para participar que los diferentes actores educativos declaran haber tenido según período de análisis}

\begin{tabular}{|c|c|c|c|}
\hline & $\begin{array}{c}\text { Etapa de } \\
\text { preocupación por } \\
\text { la calidad educativa } \\
(1980-1989)\end{array}$ & $\begin{array}{c}\text { Etapa de } \\
\text { emprendimiento de } \\
\text { proyectos educativos } \\
(1990-1999)\end{array}$ & $\begin{array}{l}\text { Etapa de fortalecimiento institucional } \\
\qquad(2000-2017)\end{array}$ \\
\hline $\begin{array}{l}\text { Tipos de } \\
\text { motivación } \\
\text { en la } \\
\text { institución } \\
\text { educativa }\end{array}$ & $\begin{array}{l}\text { Motivación por la } \\
\text { preocupación de los } \\
\text { padres } \\
\text { Motivación porque } \\
\text { la comunidad se } \\
\text { acostumbró a ser } \\
\text { solidaria } \\
\text { Motivación por el } \\
\text { trabajo común para } \\
\text { todos } \\
\text { Motivación porque } \\
\text { la institución } \\
\text { educativa ayuda a la } \\
\text { capacitación de los } \\
\text { docentes } \\
\text { Motivación por } \\
\text { el impulso al } \\
\text { fortalecimiento } \\
\text { profesional del } \\
\text { docente (maestro } \\
\text { fortalecido/puedo } \\
\text { decir que soy } \\
\text { maestro) }\end{array}$ & $\begin{array}{l}\text { Motivación porque } \\
\text { se promueve la } \\
\text { participación } \\
\text { Motivación porque } \\
\text { se habla con nosotros } \\
\text { (hermanas) los padres } \\
\text { Motivación porque } \\
\text { la institución } \\
\text { educativa ayuda a la } \\
\text { capacitación de los } \\
\text { docentes } \\
\text { Motivación } \\
\text { por el apoyo al } \\
\text { fortalecimiento } \\
\text { profesional del } \\
\text { docente (maestro } \\
\text { fortalecido/puedo } \\
\text { decir que soy } \\
\text { maestro) }\end{array}$ & 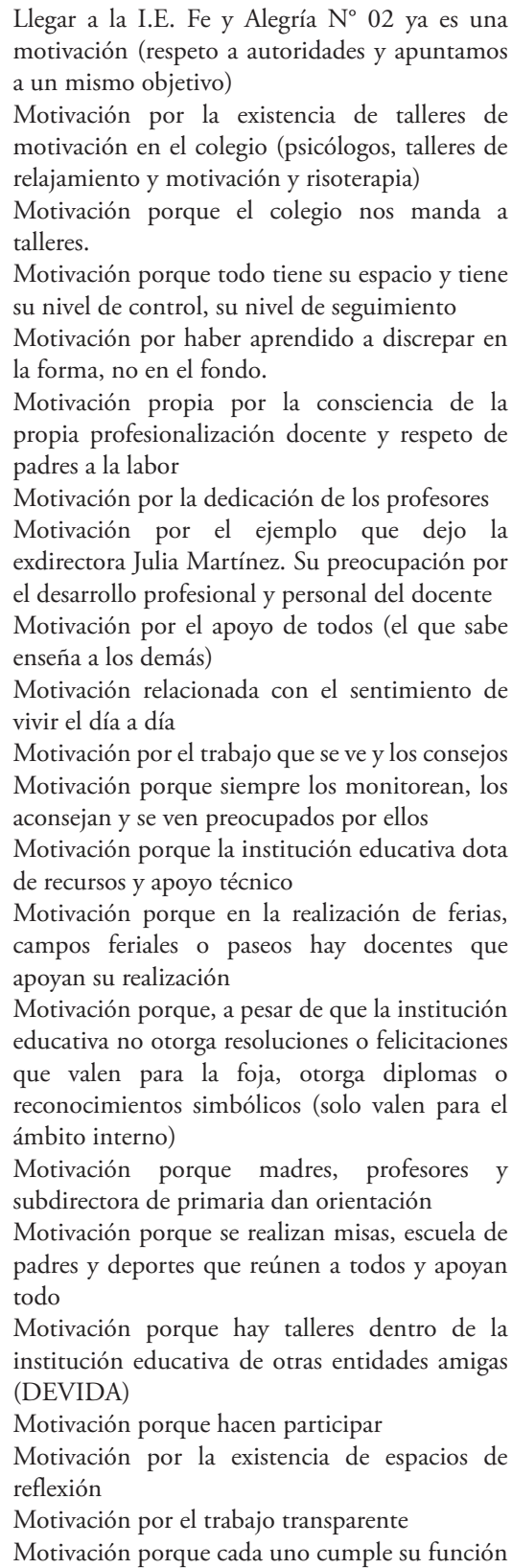 \\
\hline
\end{tabular}




\section{Tabla 5. Fortalezas de la I.E. Fe y Alegría Nº 02 identificadas por los entrevistados aglomerados según período de análisis}

\begin{tabular}{|c|c|c|c|}
\hline & $\begin{array}{l}\text { Etapa de preocupación por la } \\
\text { calidad educativa (1980-1989) }\end{array}$ & $\begin{array}{c}\text { Etapa de emprendimiento } \\
\text { de proyectos educativos } \\
(1990-1999)\end{array}$ & $\begin{array}{l}\text { Etapa de fortalecimiento } \\
\text { institucional (2000-2017) }\end{array}$ \\
\hline \multirow{23}{*}{$\begin{array}{l}\text { Fortalezas } \\
\text { de la IE }\end{array}$} & \multirow{6}{*}{$\begin{array}{l}\text { Enseñanza } \\
\text { Abnegación de las hermanas } \\
\text { Cualidades éticas de las } \\
\text { hermanas (muy correctas)*** } \\
\text { Disciplina impartida por las } \\
\text { hermanas*** }\end{array}$} & \multirow{10}{*}{$\begin{array}{l}\text { Unión (de los padres) }{ }^{* * *} \\
\text { Homologación entre profesores } \\
\text { contratados y nombrados } \\
\text { Apoyo de la Oficina Central Fe } \\
\text { y Alegría } \\
\text { Disciplina más estricta*** } \\
\text { Cualidades éticas y } \\
\text { comunicativas de las hermanas } \\
\text { (saber escuchar, rectas y } \\
\text { buenas)*** }\end{array}$} & Unión $(3)^{* * *}$ \\
\hline & & & Disciplina $(2)^{* * *}$ \\
\hline & & & Organización del colegio (8) \\
\hline & & & Trabajo y ejemplo de los \\
\hline & & & colegas (docentes antiguos o \\
\hline & & & formación en el trabajo que se \\
\hline & \multirow{7}{*}{$\begin{array}{l}\text { Padres y madres muy } \\
\text { responsables y dedicados } \\
\text { Ayuda mutua*** } \\
\text { Sentimiento de familia** } \\
\text { Se estaba pendiente uno del } \\
\text { otro*** } \\
\text { Solidaridad de los padres de } \\
\text { familia*** }\end{array}$} & & fue trasmitiendo) \\
\hline & & & Estabilidad \\
\hline & & & Capacitación del área EPT \\
\hline & & & Continua capacitación \\
\hline & & & $\begin{array}{l}\text { Ayuda, apoyo, cooperación, } \\
\text { solidaridad entre diferentes }\end{array}$ \\
\hline & & & actores $(7)^{* * *}$ \\
\hline & & & Innovación permanente (2) \\
\hline & \multirow{10}{*}{$\begin{array}{l}\text { Supervisión constante de la } \\
\text { directora }\end{array}$} & & Planificación previa a fin de año \\
\hline & & & $\begin{array}{l}\text { Aprender, compartir o } \\
\text { potenciar habilidades (5) }\end{array}$ \\
\hline & & & Comunicación $(5)^{* * *}$ \\
\hline & & & Confianza entre los actores** \\
\hline & & & Trabajo en grupo \\
\hline & & & Una familia** \\
\hline & & & $\begin{array}{l}\text { Espacios que permiten a las } \\
\text { personas conocerse** }^{* *}\end{array}$ \\
\hline & & & $\begin{array}{l}\text { Tomar en cuenta la opinión de } \\
\text { los padres }\end{array}$ \\
\hline & & & Mística de la IE \\
\hline & & & $\begin{array}{l}\text { Fortalecimiento de lazos de } \\
\text { amistad }^{* *}\end{array}$ \\
\hline
\end{tabular}

Fuente: Elaboración propia. ${ }^{* *}=$ se repite en los tres períodos, ${ }^{* *}=$ se repite en dos períodos, si no aparece un ${ }^{*}=$ solo se hace mención en un período de análisis y () = número de veces que se hace mención por un actor diferente. 